\title{
Subjective Reactions to International Research Participation: An Illustration of Ethical Considerations With Women Heading Households in Sri Lanka
}

\author{
Jessica E. Lambert \\ California State University - Stanislaus \\ Alyssa Banford Witting \\ Brigham Young University - Provo, alyssa_banfordwitting@byu.edu \\ Lakmal Ponnamperuma \\ Kaatsu International University \\ Thulitha Wickrama \\ University of Colombo \\ Follow this and additional works at: https://scholarsarchive.byu.edu/facpub \\ Part of the Other Social and Behavioral Sciences Commons
}

\section{Original Publication Citation}

Lambert, J., Banford Witting, A.,Ponnamperuma, L., \& Wickrama, T. (2017). Subjective reactions to international research participation: An illustration of ethical considerations with women heading households in Sri Lanka. American Journal of Orthopsychiatry.

\section{BYU ScholarsArchive Citation}

Lambert, Jessica E.; Witting, Alyssa Banford; Ponnamperuma, Lakmal; and Wickrama, Thulitha, "Subjective Reactions to International Research Participation: An Illustration of Ethical Considerations With Women Heading Households in Sri Lanka" (2017). Faculty Publications. 4063.

https://scholarsarchive.byu.edu/facpub/4063

This Peer-Reviewed Article is brought to you for free and open access by BYU ScholarsArchive. It has been accepted for inclusion in Faculty Publications by an authorized administrator of BYU ScholarsArchive. For more information, please contact ellen_amatangelo@byu.edu. 


\title{
Subjective Reactions to International Research Participation: An Illustration of Ethical Considerations With Women Heading Households in Sri Lanka
}

\author{
Jessica E. Lambert \\ California State University, Stanislaus \\ Lakmal Ponnamperuma \\ Kaatsu International University
}

\author{
Alyssa Banford Witting \\ Alliant International University \\ Thulitha Wickrama \\ University of Colombo
}

\begin{abstract}
There are unique ethical considerations in conducting international research with war and disaster-affected populations that are important for ensuring adequate protection of participants. Of particular importance is the distress that participants may experience as a result of being asked about traumatic stressors, psychological symptoms, and life problems. In this study, traumaaffected Tamil women in Eastern Sri Lanka were asked to report on their research-participation experience after taking part in a larger study on risk and resiliency. Results indicated that most participants experienced emotional upset as a result of taking part in the study. However, the degree of distress was generally not more than they anticipated, and most participants reported they would have participated had they known in advance how they would feel. Most participants perceived some benefit as a result of participating and agreed that items were personally relevant. Emotional distress from participation positively correlated with culturally specific symptoms of anxiety and depression. Contextual stressors and social support were not associated with participation-related distress. We discuss these findings as well as general issues that might arise in international research with trauma-affected populations.
\end{abstract}

\begin{abstract}
Public Policy Relevance Statement
Understanding the potential burden of research participation is essential for planning ethical studies with vulnerable populations. Risks associated with psychological research can be difficult to identify but need to be considered to ensure adequate protection of participants. This study examined the subjective emotional reactions to research participation among a sample of war- and disaster-affected Tamil women in Sri Lanka to shed light on potential ethical concerns for research with this and other populations in postconflict, low-resource settings.
\end{abstract}

$\mathbf{W}$ ell-designed research with populations affected by war or disaster in low-resource countries has the potential to yield vital information for planning appropriate psychosocial interventions, especially in areas lacking a

This article was published Online First June 19, 2017.

Jessica E. Lambert, Psychology and Child Development Department, California State University, Stanislaus; Alyssa Banford Witting, Couple and Family Therapy Programs, Alliant International University; Lakmal Ponnamperuma, Department of Psychology, Kaatsu International University; Thulitha Wickrama, Clinical Psychology Graduate Program, University of Colombo.

Correspondence concerning this article should be addressed to Jessica E. Lambert, Psychology and Child Development Department, California State University, Stanislaus, 1 University Cr, Bizzini Hall 230 Turlock, CA 95382. E-mail: jlambert@csustan.edu strong mental health infrastructure. International research with vulnerable populations, however, involves unique ethical considerations to ensure adequate protection of participants (Mackenzie, McDowell, \& Pittaway, 2007; Pittaway, Bartolomei, \& Hugman, 2010). Informed consent, for example, takes on an added layer of complexity when working cross-culturally. Well-meaning researchers may unintentionally coerce participation by offering substantial remuneration or not adequately conveying the voluntary nature of participation (Bhutta, 2004; Ellis, Kia-Keating, Yusuf, Lincoln, \& Nur, 2007; Pittaway et al., 2010). In areas with ongoing political turmoil, disclosing information to researchers could put participants and their family members at risk (Beyrer \& Kass, 2002). Recently traumatized populations faced with ongoing difficult life circumstances may also experience undue emotional distress when asked to report on topics like exposure to violence, traumatic loss, and psychological symptoms. Discussion of sensi- 
tive topics is potentially inconsistent with cultural norms, and psychological measures developed in Western contexts may not be relevant for the population. For these reasons, ensuring an adequate balance of potential risks to participants and tangible benefits of the research is essential (Allden et al., 2009; Ellis et al., 2007).

In this study, we evaluated the burden of taking part in traumafocused research among a sample of Tamil women who were heads of their households in the Eastern Province, Sri Lanka. We report results of a questionnaire assessing subjective reactions to research that was part of a larger study on the mental health status of women exposed to political violence and the 2004 tsunami (Witting, Lambert, \& Wickrama, 2016). We were interested in assessing women's subjective experience of participation in the research, including perceived benefit, emotional distress experienced as a result of participating, and whether they believed the questions asked were personally relevant. We were also interested in associations of subjective reactions with psychological distress and contextual factors, including social support, family cohesion, and contextual problems.

The emotional burden of participating in trauma-focused research is an important ethical consideration that is often raised by institutional review boards, given that participants are potentially vulnerable. Questions about exposure to trauma and psychological symptoms have the potential to evoke emotional distress (Newman, Walker, \& Gefland, 1999). Reactions of individual participants are likely to vary and could depend on their general level of psychological distress, the extent to which they experience ongoing life stressors, or the degree of support they have from others.

Several studies have explored the impacts of research participation among samples recruited in the United States, including domestic violence survivors (Johnson \& Benight, 2003), military veterans (Ferrier-Auerbach, Erbes, \& Polusny, 2009), and adult women with a history of childhood trauma. Newman et al. (1999), for example, found that the majority of women who took part in an interview-based study on trauma experience in childhood perceived some benefit as a result of participating. Further, most women were not more upset than they anticipated and the majority reported no regrets over their decision to participate. Similarly, in Johnson and Benight's (2003) study of female survivors of domestic violence, most participants reported some gain and only a few expressed regret over participation. Results of these investigations suggest that participants tolerate trauma-focused research relatively well. However, results of studies on reactions to research participation in the United States may not generalize in an international context, given cultural differences in the discussion of sensitive topics, as well as contextual differences. To our knowledge, reactions to research participation among an international conflict and disaster-affected population has not been formally studied. A better understanding of participants' subjective reactions to research and the factors that are associated with researchrelated distress could have important implications for weighing potential risks of participation with potential benefits.

The cross-cultural relevance of psychological measures developed among Western samples is also an important consideration in international research, particularly when measures are translated into the local language. Recommended guidelines for validating measures include using a back-translation procedure, followed by focus-group discussions with members of the population to determine the relevance of items, and piloting measures to evaluate the psychometric properties (e.g., Hambleton, 2005; Sousa \& Rojjanasrirat, 2011). In this study, we were interested in the overall perceived relevance of the questionnaires. Although perceived relevance did not provide information on the psychometric properties or construct validity of our measures, given the lack of research with this population, we saw this study as a first step toward understanding whether the measures we selected were assessing topics relevant to the population.

\section{Research Context}

Since gaining independence from Great Britain in 1948, Sri Lanka has been plagued by violence and disaster. First, there were two Marxist insurgencies and their accompanying military interventions in the 1970s and 1980s. These events were followed by civil war, beginning in 1983 and lasting nearly three decades (Chatterjee \& Jeganathan, 2000). Casualties of these conflicts have been high, with over 200,000 dead and millions more displaced or otherwise affected (Obermeyer, Murray, \& Gakidou, 2008). Moreover, these events left behind a culture of fear that continues to be present, despite the war ending in 2009.

One consequence of the protracted conflict was a substantial change in the demographics of many of the communities in the Northern and Eastern Provinces, particularly the increase in woman-headed households due to death and migration. Challenges faced by widows and other women heading households include poverty, lack of economic opportunity, and stigma. Rising out of poverty is precluded by difficulties securing gainful employment (Premaratne \& Klimešová, 2015). War-affected women in Sri Lanka also show psychological symptoms such as prolonged grief, depressive symptoms, and posttraumatic reactions (Husain et al., 2011; Siriwardhana et al., 2013). These problems are often maintained by illiteracy, lack of formal education, lack of social support, and discrimination toward women (Ozer, Best, Lipsey, \& Weiss, 2003).

A consideration of the sociopolitical context and cultural norms regarding discussion of potentially sensitive topics is essential when conducting international research. Several contextual factors hold bearing on research with war-affected women in Sri Lanka. For instance, Tamil Hindu culture traditionally shows negative attitudes toward widowhood, thus contributing to internalized stigma (Premaratne \& Klimešová, 2015). These women are also vulnerable to marginalization if they or their husbands were combatants or if they were sexually assaulted (Premaratne \& Klimešová, 2015). Therefore, questions related to political views, attitudes toward civil war and government, or involvement in combat are highly sensitive and even potentially dangerous for participants to answer, as are questions regarding the experience of sexual violence (Wood, 2006). Questions on current security status and torture-related experiences were not included in the current study because of the controversy over United Nations requests for an independent inquiry into war crimes shortly before the data collection began (United Nations News Centre, 2014). 


\section{Present Study}

In this study, we examined the subjective reactions to research participation of a sample of war and disaster-affected Tamil women heading households in the Eastern Provence of Sri Lanka. We were specifically interested in emotional reactions associated with participation, whether they perceived some benefit from taking part, and if they believed questions were personally relevant. Regarding emotional reactions, we asked participants if taking part made them sad or upset, whether this distress was more than expected based on the description of the study given in the informed consent, and if they still would have participated if they had known how they would feel. We evaluated correlations between specific reactions and severity of depression and anxiety symptoms. We hypothesized that participants with higher scores on measures of psychological distress would also report more emotional distress and more regret over participation. We also evaluated correlations between emotional reactions and contextual variables, including social support, family cohesion, and contextual problems. We anticipated that women who reported higher social support and family cohesion would have more favorable reactions to research participation, whereas those with relatively more ongoing contextual stressors would have more negative reactions to participation.

\section{Method}

\section{Participants}

This study received approval from the Institutional Review Board of Alliant International University. The title of the study was "War and Disaster: Experiences of Sri Lankan Women." The sample for the current study was comprised of 198 Tamil women who identified as heads of household living in a rural area in the Eastern Province of Sri Lanka. The women in the sample spoke Tamil, which is the minority language in Sri Lanka. Most identified as Hindu. The average age of the women in the sample was 54.55 and the sample ranged in age from 21 to 80 . On average, the women in the sample had four children $(N=187)$, and were living in a variety of settings. Approximately $4 \%$ of the women were living in relief centers, $15.2 \%$ were in temporary housing, $22.7 \%$ were living with family and friends, $35.9 \%$ were living in their own home and reported that it had sustained damages, $8.6 \%$ were living in their own homes without damages, and $10.1 \%$ reported an "other" housing condition. The average income in the past year (from spring, 2013 to spring, 2014) was reported to be $67,075.93$ Sri Lanka rupees, which currently equates to approximately $\$ 462.13(N=113)$.

\section{Measures}

Reactions to research participation. We used a modified version of the Reactions to Research Participation Questionnaire-Revised (Newman, Willard, Sinclair, \& Kaloupek, 2001). We included the three items that have been examined in other studies of trauma-affected populations (Johnson \& Benight, 2003; Newman et al., 1999): "I gained something positive from participating in this research," "Participating in this research made me more upset than anticipated," and "Had I known in advance what participating in this research would be like for me, I still would have agreed." We included two additional items: "Participating in this research made me feel sad or upset," and "The questions asked were relevant to me." All items were answered on a 5-point scale ranging from $1=$ strongly disagree to $5=$ strongly agree. Consistent with previous studies (e.g., Johnson \& Benight, 2003; Newman et al., 1999), we examined responses on individual items rather than a total score.

Contextual problems, anxiety, and depression. Contextual problems, as well as severity of depression and anxiety-related symptoms, were assessed with the Penn/RESIST/ Peradeniya War Problems Questionnaire (PRPWPQ; Jayawickreme, Jayawickreme, Goonasekera, \& Foa, 2009), which was developed specifically for war-affected Tamil participants in Sri Lanka. The first part of the scale assesses the frequency of various war-related problems found to be salient in a qualitative study of the population. The measure has six subscales: War-Related Family Problems, Economic Problems, Social Problems, Shame Problems, Problems With Meeting Basic Needs, and Physical Problems. Participants responded to items based on whether or not the statement applied to them (yes/no). Example problems include separation from family members, lack of food, and stress of moving to a new place. In this study, we used a summed total scale as an indicator of the number of contextual problems.

The symptom scale from the PRPWPQ (Jayawickreme, Jayawickreme, Goonasekera, \& Foa, 2009) is a measure of psychological distress developed from qualitative interviews with waraffected Sri Lankan Tamils. Participants responded on items indicating the degree to which they experienced specific symptoms on a scale ranging from 1 (not at all) to 5 (extremely). Items reflect local idioms of distress. The subscales, created through factor analysis, are similar to anxiety and depression. Cronbach's alpha for the Depression subscale (22-items) was $\alpha=.89$, and for the Anxiety subscale (20-items), $\alpha=.83$. Jayawickreme, Jayawickreme, Atanasov, Goonasekera, \& Foa (2012) found that these scales were better predictors of functional impairment than psychopathology measures developed for use in Western contexts.

Family cohesion. Family cohesion was assessed and measured using the general family-functioning subscale of the Family Assessment Device (Epstein, Baldwin, \& Bishop, 1983). In the current study, the three items that were originally written in English to be reverse-scored were dropped to improve internal consistency because they had the lowest interitem correlations. Cronbach's alpha for the original 12-item scale was $\alpha=.61$; after dropping the three items, this improved to $\alpha=.81$. Given that the three problematic items were those that were reverse-scored, there may have been miscommunications during administration or misunderstanding of the translated items. The three items in question were: "There are lots of bad feelings in our family," "We avoid discussing our fears and concerns," and "Making decisions is a problem for our family." It appears that reverse-coded items may have been unclear in their translation, which lead to a lack of internal consistency in the measure. Scale totals were created by summing scores on the individual scales. 
Social support from community. Social support from community and neighbors was assessed with a subscale of a social support measure. The original measure was developed for use in Wickrama and Wickrama's (2008) study of Sri Lankan tsunami survivors. Items are rated on a Likert scale ranging from 1 (never) to 5 (always). The 4-item Community Support scale is composed of items assessing perception of community support, including "Neighbors help each other in times of trouble" and "Neighbors participate in community activities." Scores for the whole scale can range from 4 to 20, with higher scores indicating greater support. For this subscale, $\alpha=.82$.

\section{Procedure}

Before collecting data, the study was approved by the institutional review board of the sponsoring academic institution. The survey questionnaire for the study was translated and then backtranslated for use in Tamil by two bilingual academics. A list of women heading households was obtained from the statistics division of the local district government administrative office. Two research assistants used this list, which included the residence of the women, to recruit participants. Research assistants approached potential participants on foot at their place of residence, and invited them to participate in the study. Study respondents were given a small cash incentive for their participation.

\section{Results: Bivariate Analyses}

The vast majority (91\%) of participants reported that they gained something positive from taking part in the study, with $50.1 \%$ agreeing with this statement and $40.9 \%$ strongly agreeing. Most (66.2\%) also reported that taking part made them feel sad or upset; approximately $20 \%$ disagreed or strongly disagreed the study had made them feel upset and the remainder reported being neutral. Slightly more than $35 \%$ of participants indicated that participation was more distressing than they anticipated, but most $(89 \%)$ reported that they would have participated even if they had they known in advance what it would be like for them. Last, $80.8 \%$ of participants agreed or strongly agreed that questions were personally relevant.

Next, we examined bivariate correlations between reactions to research items and indicators of psychological distress (see Table 1). Because the item regarding perceived benefit was severely negatively skewed, with over $90 \%$ of the sample scoring 4 or 5 (indicating benefit), it was not included in the correlation analyses. Participants who reported feeling sad or upset as a result of research participation also tended to report more severe anxiety

Table 1. Bivariate Correlations for Reaction to Research Items

\begin{tabular}{lcccccc}
\hline \multicolumn{1}{c}{ Variable } & 1 & 2 & 3 & 4 & 5 & 6 \\
\hline 1. Sad or upset & - & $.43^{* * *}$ & $.17^{*}$ & .04 & $.25^{* * *}$ & $.37^{* *}$ \\
2. More upset than expected & & - & -.09 & -.01 & $.27^{* * *}$ & $.26^{* *}$ \\
3. Still would have participated & & & $.41^{* *}$ & .01 & .03 \\
4. Relevance & & & & - & .07 & .02 \\
5. Anxiety & & & & - & $.47^{* *}$ \\
6. Depression & & & & & - \\
\hline
\end{tabular}

${ }^{*} p<.05 . \quad * * p<.01$. and depression. Experiencing greater emotional upset than was anticipated also positively correlated with anxiety and depression. The items assessing whether a person would still have participated had she known how she would feel and perceived relevance of items were not significantly correlated with measures of distress.

We also estimated correlations between research-participation items and contextual variables to determine whether reactions to research were correlated with general level of psychosocial problems, degree of social support in one's community, and family cohesion (see Table 2). Most correlations were nonsignificant, and those that were statistically significant were small in magnitude. There was a significant association between contextual problems and expectations of distress, such that individuals who reported more problems were less likely to report unexpected emotional distress. Those who reported more contextual problems also tended to view the items as less relevant. In addition, individuals who reported higher family cohesion were more likely to agree that they would have still participated had they known how they would feel and perceived the items as more relevant.

\section{Discussion}

In this study, we evaluated subjective experiences of research participation among a sample of women heading households in eastern Sri Lanka. The sample is notable because they were members of the disadvantaged ethnic Tamil group and were both war and disasteraffected. To our knowledge, this is the first quantitative investigation of reactions to research participation among this population. Results suggest that the research was relatively well-tolerated, and the majority reported some benefit from participation. Although a majority of participants reported sadness or emotional upset as a result of taking part, they also indicated that distress was generally not more than anticipated. Further, a substantial majority would have participated anyway if they knew ahead of time what it would be like for them. Also important, the vast majority agreed or strongly agreed that questions were relevant.

Participants who reported higher anxiety and depression also reported more emotional distress as a result of participating and were more likely to report that this distress was more than they anticipated. Contrary to expectations, the severity of contextual problems was not significantly related to distress resulting from participation. However, those with more problems were less likely to report that the study made them more upset than they anticipated, and less likely to rate the questions as relevant. Participants with more cohesive families were more likely to report that they would have participated anyway, had they known how they would feel, and also were more likely to perceive the questions as personally relevant. It should be noted that most correlations were small to moderate in magnitude.

The finding that the vast majority of participants reported some benefit is encouraging, yet should be interpreted with caution, given that there is more than one interpretation of the item. Participants were paid the equivalent of approximately $\$ 5.00$ for their participation; thus the perceived benefit could have been financial gain. This amount of compensation was relatively large given the yearly income of the sample, which was lower than that of the local population. It is possible that participants responded favorably to questions regarding research participation because of the cash incentive. The idea of subjective perceptions of benefit is important, however, given that 
Table 2. Bivariate Correlations for Reaction to Research Items

\begin{tabular}{lcccccrr}
\hline \multicolumn{1}{c}{ Variable } & 1 & 2 & 3 & 4 & 5 & 6 & 7 \\
\hline 1. Sad or upset & - & $.43^{* *}$ & $.17^{*}$ & .04 & .01 & -.04 & .09 \\
2. More upset than expected & & - & -.09 & -.01 & $-.31^{* *}$ & .01 & .04 \\
3. Still would have participated & & & - & $.41^{* *}$ & .04 & .07 & $.15^{*}$ \\
4. Relevance & & & & - & $-.16^{*}$ & .13 & $.21^{*}$ \\
5. Problems & & & & - & $-.52^{* *}$ & $-.34^{* *}$ \\
6. Support & & & & & - & $.27^{* * *}$ \\
7. Family cohesion & & & & & & - \\
\hline
\end{tabular}

${ }^{*} p<.05 . \quad{ }^{* *} p<.01$.

participants often do not directly experience tangible benefits from academic research. Studies on research participation among United States samples of trauma survivors have shown that research subjects perceive some benefit from participation (Johnson \& Benight, 2003; Newman et al., 1999), especially if data were collected using interviews as opposed to surveys (Newman et al., 1999). It is possible that there is some therapeutic benefit received from emotional disclosure during the interview; however, this proposition requires empirical investigation.

It is important to address the finding that most participants reported feeling sad or upset as a result of participation. This finding raises the ethical consideration of whether the overall benefit of the research outweighs the immediate emotional consequences for the participants. Given that over $80 \%$ reported they would have participated even knowing how they would feel, it appears that despite the distress, participants did not regret taking part.

Participants who reported more severe symptoms of anxiety and depression also reported more distress related to participating in the study. This finding is consistent with Johnson and Benight's (2003) findings that female survivors of intimate-partner violence experienced more distress associated with participation when they had more severe depression and posttraumatic stress symptoms. Contextual problems, however, were not correlated with participation-related distress. Participants who reported more problems were actually less likely to report experiencing more distress than expected as a result of taking part in the study. It is important to note that it is possible that participants underreported contextual problems because of the political climate in Sri Lanka when the data were collected. As mentioned earlier, our study took place around the same time the United Nations announced a resolution for an independent investigation into war crimes (UN News Centre, 2014). There were widespread concerns in communities around the country about disclosing war-related experiences.

Some of the most commonly raised ethical concerns about international research in developing countries are related to the adequacy of the consent process (Bhutta, 2004; Ellis et al., 2007; Leaning, 2001; Pittaway et al., 2010). Informed-consent procedures typical in Western cultures may be unfamiliar in other contexts. Participants may vary in functional literacy, and the legal consent-form terminology used may not translate adequately into the local language (Wessells, 2009). As a consequence, there could be misunderstandings of what participants think is expected of them. In our study, most participants were no more upset than they expected, suggesting that they had a reasonable understanding from the consent procedures of what would be asked of them and how it would make them feel.

\section{Limitations and Future Research}

Our findings that research involving sensitive questions was well-tolerated by a trauma-affected population must be interpreted with respect to limitations. Our results are focused on emotional reactions of perceptions of relevance. Although important, this does not address larger concerns raised in the literature regarding potential coercion of participants resulting from power differentials (Leaning, 2001) or misunderstandings between researchers and participants. Data were collected using interviews. As such, findings are subject to potential biases and underreporting of distress, especially if participants were responding in ways they felt were socially acceptable.

As with all cross-cultural research, protocols that are not culturally sensitive are not likely to yield meaningful information (Allden et al., 2009). Validity issues are of particular importance when data are used to make decisions regarding resource allocation, program development, or psychological interventions (Beyrer $\&$ Kass, 2002). In this study, we used a measure specifically developed for the Sri Lanka population to assess contextual problems and psychological distress. The other measures had been used in previous research with this population. Nevertheless, it is possible we missed important concerns that our participants experienced. The inclusion of a qualitative component to the study could address this issue in future research.

Future research on reactions to research participation with traumaaffected populations could include a more detailed description of participant reactions using qualitative interviews. For example, it would be useful to explore the topic of perceived benefit further to clarify whether it is related to sharing their experiences, the remuneration offered, or other factors. It may also be useful, particularly for exploratory research, to gather more specific information on the perceived relevance of the questions participants were asked.

\section{Conclusion}

Results of this study demonstrate that, although participation in trauma-focused research is associated with psychological distress, the majority of participants would have participated anyway, even had they known in advance how it would make them feel. This finding is encouraging, given ethical concerns in research with trauma-affected populations. The finding that women with high levels of psychological distress experienced greater emotional upset as a result of participation underscores the importance of providing referrals or even interventions for participants. 
We were also encouraged by the finding that most participants found the study questions relevant. This, however, does not necessarily confirm the validity of the measures. The validity of the results of international research is essential to consider, particularly when findings are used to inform policy or resource allocation. Careful planning and knowledge of local concerns and cultural norms can mitigate research-related risks to some degree (Allden et al., 2009). An important first step is learning about the sociopolitical context in which the study will be conducted. Beyond prevention of harm, it is important that the research holds benefit for the population studied, not just the scientific community (Allden et al., 2009; Ellis et al., 2007). As Pittaway et al. (2010) noted, "The ethical challenge is for researchers to add value to the lives of the people they are researching, recognizing them as subjects in the process and not simply as sources of data (p. 231)."

Keywords: research ethics; international research; widows; waraffected; disaster-affected

\section{References}

Allden, K., Jones, L., Weissbecker, I., Wessells, M., Bolton, P., Betancourt, T. S., ... Sumathipala, A. (2009). Mental health and psychosocial support in crisis and conflict: Report of the Mental Health Working Group. Prehospital and Disaster Medicine, 24, s217-s227. http://dx.doi .org/10.1017/S1049023X00021622

Beyrer, C., \& Kass, N. E. (2002). Human rights, politics, and reviews of research ethics. Lancet, 360, 246-251. http://dx.doi.org/10.1016/S01406736(02)09465-5

Bhutta, Z. A. (2004). Beyond informed consent. Bulletin of the World Health Organization, 82, 771-777. http://dx.doi.org/10.1590/S004296862004001000013

Chatterjee, P., \& Jeganathan, P. (2000). Community, gender and violence. New York, NY: Columbia University Press.

Ellis, B. H., Kia-Keating, M., Yusuf, S. A., Lincoln, A., \& Nur, A. (2007). Ethical research in refugee communities and the use of community participatory methods. Transcultural Psychiatry, 44, 459-481. http://dx .doi.org/10.1177/1363461507081642

Epstein, N. B., Baldwin, L. M., \& Bishop, D. S. (1983). The McMaster Family Assessment Device. Journal of Marital and Family Therapy, 9, 171-180. http://dx.doi.org/10.1111/j.1752-0606.1983.tb01497.x

Ferrier-Auerbach, A. G., Erbes, C. R., \& Polusny, M. A. (2009). Does trauma survey research cause more distress than other types of survey research? Journal of Traumatic Stress, 22, 320-323. http://dx.doi.org/ $10.1002 /$ jts. 20416

Hambleton, R. K. (2005). Issues, designs, and technical guidelines for adapting tests into multiple languages and cultures. In R. K. Hambleton, P. F. Merenda, \& C. D. Spielberger (Eds.), Adapting educational and psychological tests for cross-cultural assessment (pp. 3-38). Mahwah, NJ: Erlbaum.

Husain, F., Anderson, M., Lopes Cardozo, B., Becknell, K., Blanton, C., Araki, D., \& Vithana, E. K. (2011). Prevalence of war-related mental health conditions and association with displacement status in postwar Jaffna District, Sri Lanka. Journal of the American Medical Association, 306, 522-531. http://dx.doi.org/10.1001/jama.2011.1052

Jayawickreme, N., Jayawickreme, E., Atanasov, P., Goonasekera, M. A., \& Foa, E. B. (2012). Are culturally specific measures of trauma-related anxiety and depression needed? The case of Sri Lanka. Psychological Assessment, 24, 791-800. http://dx.doi.org/10.1037/a0027564

Jayawickreme, N., Jayawickreme, E., Goonasekera, M. A., \& Foa, E. B. (2009). Distress, wellbeing and war: Qualitative analyses of civilian interviews from north eastern Sri Lanka. Intervention, 7, 204-222. http://dx.doi.org/10.1097/WTF.0b013e328334636f

Johnson, L. E., \& Benight, C. C. (2003). Effects of trauma-focused research on recent domestic violence survivors. Journal of Traumatic Stress, 16, 567-571. http://dx.doi.org/10.1023/B:JOTS.0000004080 $.50361 . \mathrm{f3}$

Leaning, J. (2001). Ethics of research in refugee populations. Lancet, 357, 1432-1433. http://dx.doi.org/10.1016/S0140-6736(00)04572-4

Mackenzie, C., McDowell, C., \& Pittaway, E. (2007). Beyond 'do no harm': The challenge of constructing ethical relationships in refugee research. Journal of Refugee Studies, 20, 299-319. http://dx.doi.org/10 $.1093 / \mathrm{jrs} / \mathrm{fem} 008$

Newman, E., Walker, E. A., \& Gefland, A. (1999). Assessing the ethical costs and benefits of trauma-focused research. General Hospital Psychiatry, 21, 187-196. http://dx.doi.org/10.1016/S0163-8343(99)00011-0

Newman, E., Willard, T., Sinclair, R., \& Kaloupek, D. (2001). Empirically supported ethical research practice: The costs and benefits of research from the participants' view. Accountability in Research, 8, 309-329.

Obermeyer, Z., Murray, C. J., \& Gakidou, E. (2008). Fifty years of violent war deaths from Vietnam to Bosnia: Analysis of data from the World Health Survey Programme. The British Medical Journal, 336, 1482 1486. http://dx.doi.org/10.1136/bmj.a137

Ozer, E. J., Best, S. R., Lipsey, T. L., \& Weiss, D. S. (2003). Predictors of posttraumatic stress disorder and symptoms in adults: A meta-analysis. Psychological Bulletin, 129, 52-73. http://dx.doi.org/10.1037/0033-2909 .129.1.52

Pittaway, E., Bartolomei, L., \& Hugman, R. (2010). 'Stop stealing our stories': The ethics of research with vulnerable groups. Journal of Human Rights Practice, 2, 229-251. http://dx.doi.org/10.1093/jhuman/ huq004

Premaratne, B., \& Klimešová, M. (2015). Empowering Tamil women: Recovery in post-conflict Sri Lanka (1st ed.). Stockholm, Sweden: The Institute for Security and Development Policy.

Siriwardhana, C., Adikari, A., Pannala, G., Siribaddana, S., Abas, M., Sumathipala, A., \& Stewart, R. (2013). Prolonged internal displacement and common mental disorders in Sri Lanka: The COMRAID study. PLOS ONE, 8, e64742. http://dx.doi.org/10.1371/journal.pone.0064742

Sousa, V. D., \& Rojjanasrirat, W. (2011). Translation, adaptation and validation of instruments or scales for use in cross-cultural health care research: A clear and user-friendly guideline. Journal of Evaluation in Clinical Practice, 17, 268-274. http://dx.doi.org/10.1111/j.1365-2753 .2010 .01434 .x

United Nations News Centre. (2014, March 27). UN rights council approves inquiry into alleged abuses in Sri Lanka war. United Nations News Service. Retrieved from http://www.un.org/apps/news/story .asp? NewsID $=47447 \% 23$. WDSjAn3G85w

Wessells, M. G. (2009). Do no harm: Toward contextually appropriate psychosocial support in international emergencies. American Psychologist, 64, 842-854. http://dx.doi.org/10.1037/0003-066X.64.8.842

Wickrama, K. A. S., \& Wickrama, K. A. (2008). Family context of mental health risk in Tsunami affected mothers: Findings from a pilot study in Sri Lanka. Social Science \& Medicine, 66, 994-1007. http://dx.doi.org/ 10.1016/j.socscimed.2007.11.012

Witting, A. B., Lambert, J., \& Wickrama, T. (2016). War and disaster in Sri Lanka: Implications for widows' family adjustment and perception of self-efficacy in caring for one's family. International Journal of Psychology, Advance online publication. http://dx.doi.org/10.1002/ijop .12407

Wood, E. (2006). The ethical challenges of field research in conflict zones. Qualitative Sociology, 29, 373-386. http://dx.doi.org/10.1007/s11133006-9027-8 